\title{
Santo Domingo, Alma Mater de San Marcos y La Casona, Identidad, Patrimonio y Turismo en Lima
}

\author{
Santo Domingo, Alma Mater of San Marcos and La Casona, \\ Identity, Heritage and Tourism in Lima
}

\begin{abstract}
RESUMEN
Los claustros de Santo Domingo fueron el primer testimonio de la existencia de la Universidad Nacional Mayor de San Marcos, sin duda alguna una joya arquitectónica y artística religiosa de la ciudad de Lima valorada por su patrimonio material inmueble. La Casona es igualmente un valioso testimonio que destacar de la vida virreinal, emancipadora y republicana del Perú, por tanto, es importante reconocer en ambas su valiosa contribución a la cultura peruana y a la identidad nacional por el patrimonio cultural que ostentan. En la actualidad, el turismo, une a ambas, como resultado de este vínculo histórico cultural a través del conocimiento y difusión en la actividad turística.
\end{abstract}

Palabras claves: Patrimonio histórico y cultural; identidad; turismo.

\begin{abstract}
The cloisters of Santo Domingo were the first testimony of the existence of the Universidad Nacional Mayor de San Marcos, without a doubt a religious architectural and artistic jewel of the city of Lima valued for its real material heritage. La Casona is also a valuable testament to the viceroyal, emancipatory and republican life of Peru, therefore, it is important to recognize in both their valuable contribution to Peruvian culture and national identity for the cultural heritage they hold. Currently, tourism joins the two, as a result of this cultural historical link through knowledge and dissemination in tourism activity.
\end{abstract}

Keywords: Cultural historical heritage; identity; tourism.

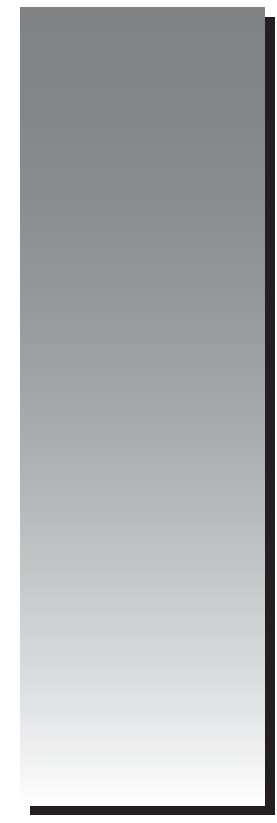

Nieves Cecilia Castillo Yui

ncastilloy@unmsm.edu.pe

Universidad Nacional Mayor de San Marcos, Facultad de Ciencias Administrativas. Lima, Perú

(C) Los autores. Este artículo es publicado por Gestión en el Tercer Milenio de la Facultad de Ciencias Administrativas de la Universidad Nacional Mayor de San Marcos. Este es un artículo de acceso abierto, distribuido bajo los términos de la licencia Creative Commons Atribucion - No Comercia_Compartir Igual 4.0 Internacional. (http://creativecommons.org/licenses/by-nc-sa/4.0/) que permite el uso no comercial, distribución y reproducción en cualquier medio, siempre que la obra original sea debidamente citada. 


\section{INTRODUCCIÓN}

Santo Domingo y La Casona, son sin duda algunos conjuntos arquitectónicos de Lima representativos de la Colonia, que, a través del turismo, aportan al conocimiento histórico e identidad peruana en el aspecto religioso e histórico, como una de las razones por las cuales la actividad turística toma responsabilidad y compromiso ante el patrimonio histórico cultural. La Sala Capitular y los claustros del convento de Santo Domingo, así como La Sala de Grados de La Casona, sus patios y la Capilla de Loreto, son, en ambos casos de gran significado para la historia del Perú, correspondiendo éstos a las primeras salas de clase donde se impartían las asignaturas de orden cívico y religioso y ambientes creados para el funcionamiento de la Universidad de San Marcos en el Siglo XVI. Igualmente, la vida de nuestros santos dominicos está evidenciada en cada espacio que ocuparon en el convento, que se trae al presente cuando se recorren y narran los hechos sucedidos con su presencia en tiempos coloniales, en el caso de Santo Domingo y en San Marcos, importantes y decididos acontecimientos de la vida intelectual e independentista del Perú, de gran importancia histórica dignos de valorar.

Por tanto, se propone a través del turismo, acciones, en los resultados, conclusiones y recomendaciones, de este trabajo, que se potencien a ambos monumentos históricos con el consiguiente beneficio de difusión, interés académico e histórico como parte de nuestra cultura, como testimonios unidos por un patrimonio e identidad a través del turismo.

La existencia del patrimonio cultural en el país tiene una estrecha relación con sus habitantes, en un contexto social y territorial donde la cultura peruana debe lograr una identidad. Ambos monumentos, como parte del patrimonio nacional se convierten en atractivos, dada su importancia en la historia y significado para el Turismo en la actualidad.

El valor que tienen ambos monumentos históricos, destacan la importancia que tuvieron en tiempos coloniales y se recuerdan en el presente; que, en la actualidad, no están libres de los estragos de la contaminación, congestión y otros malestares por su ubicación física en la capital. Es justamente la imagen de Lima Co- lonial la que hace destacar a Santo Domingo y La Casona, porque ambos testimonian valores tangibles e intangibles, así como su autenticidad, dignos de ser admirados y relacionados en la historia de Lima Colonial.

Pérez de Cuéllar (1997), dice que por la cultura se suscitan los cambios en nuestra actitud y modo de pensar, por tanto, la cultura se transmite a través del modo de ser y conducta con iniciativa propia dando oportunidad de tener nuevas razones para sostenernos en el ambiente en el cual vivimos.

A la llegada de los españoles, el hecho de fusionar ambas culturas, de hecho se pierden algunas y se adquieren otras, manteniendo costumbres y nuevas actitudes que dan por resultado una nueva cultura mestiza, siendo los dominicos parte de este cambio por la influencia que tuvieron al dirigir una formación religiosa de gran influencia para los nativos por su labor evangelizadora, conforme refiere el historiador Porras Barrenechea.

Sin embargo, así como se tiene la idea de una ciudad importante de prestigio e histórica en la época colonial, más de una vez, nos hemos preguntado, ¿qué nos hace sentir peruanos?, ¿qué características tenemos como seres humanos que compartimos un territorio, historia, patrimonio y cultura en común?, no siendo uniforme una sola fisonomía y desigualdades sociales, siendo la característica principal las diferencias que se producen por ser mestizo.

Hoy en día existe una crisis de valores, sin importar las consecuencias y problemas que esto origina en un contexto social donde se perdió el respeto para sí mismo como ser humano y la voluntad de actuar hacia un bien común. El Padre Leuridans Huys, en la revista Cultura 28 (2014), en el artículo "La familia, la escuela y los líderes de la sociedad", señala:

La pérdida de valores en el mundo construido por los adultos incluye muchos aspectos característicos de la postmodernidad: mundo tecno científico con un pensamiento positivista que excluye los valores, [...] la persona se vuelve indiferente hacia sí misma y deja de actuar porque nada le interesa, ni le parece que vale la pena el esfuerzo, sobre todo en el sec- 
tor estatal. La imagen del hombre que se impone es la del que produce y consume (pp. 16-17).

Por tanto es necesario reflexionar al respecto y darnos cuenta de que sin valores, sin base de educación familiar es muy difícil asimilar que los ciudadanos respeten lo suyo, su identidad y valores patrimoniales y sobre todo sostener los principios valorativos que debe tener el ser humano y contribuir al beneficio de sus bienes materiales e inmateriales patrimoniales con identidad a través del Turismo.

La Ley General del Patrimonio Cultural de la Nación $N^{\circ} 28296$ (2007), define al Patrimonio Cultural de la Nación como:

Se entiende por bien integrante del Patrimonio Cultural de la Nación a toda manifestación del quehacer humano -material o inmaterial- que por su importancia, valor y significado paleontológico, arqueológico, arquitectónico, histórico, artístico, militar, social, antropológico o intelectual, sea expresamente declarado como tal o sobre el que exista la presunción legal de serlo. Dichos bienes tienen la condición de propiedad pública o privada con las limitaciones que establece la presente Ley (p.5).

En 1991 es declarado el Centro Histórico de Lima como Patrimonio Mundial de la $\mathrm{Hu}$ manidad por la Organización de las Naciones Unidas para la Ciencia y la Cultura, (UNESCO), considerando sus monumentos, casonas y conjuntos religiosos que datan desde la época colonial, destacando entre éstos -La Casona de San Marcos- haciendo de Lima la ciudad más importante y representativa de las colonias de España en América del Sur.

Con sus cuatro siglos de existencia, La Casona de San Marcos se constituye como una reliquia monumental importante tanto por su arquitectura e historia como por lo que representa para la vida institucional a través del tiempo en el Perú, desde su creación en manos de los jesuitas, como noviciado, ha sido el colegio real, convictorio, cuartel, universidad y ahora Centro Cultural, claro está en diferentes circunstancias algunas de prestigio y otras nada gratas como en tiempos de la ocupación chilena, sumando a todo esto los daños que por los sismos ocurridos en Lima, la fueron deteriorando a través de su existencia en gran parte de su estructura.

La Agencia Española de Cooperación Internacional para el Desarrollo (AECID), en 1991, inicia los trabajos de restauración, en coordinación con la Universidad de San Marcos y el entonces el Instituto Nacional de Cultura (INC), culminando el trabajo en el 2011, conservando su estilo artístico original y restaurado para actividades culturales que se realizan en la actualidad, es un monumento que por su arquitectura, antigüedad de más de 400 años y significado para la vida institucional del Perú, por los acontecimientos históricos, episodios y personajes que formó, resaltan su importancia actual y trascendencia.

La Agencia Española de Cooperación Internacional para el Desarrollo, AECID (2012) nos dice que La Casona inicia sus actividades como noviciado jesuita de San Antonio Abad, considerándose como un conjunto arquitectónico destacado, el cual fue derruido por el terremoto de 1746 en Lima y reconstruido según los planos originales veintiún años después. Posteriormente, al ser expulsados los jesuitas se convierte en el Real Convictorio de San Carlos, unificando a los colegios reales de Lima hasta que en 1821, proclamada la independencia cambia de nombre por el de Colegio de San Carlos, hasta que en 1867 se convierte en la sede de nuestra universidad, siendo AECI, el propulsor de la reconstrucción arquitectónica y artística de tan preciado bien patrimonial limeño, en cuyos claustros se formaron insignes intelectuales de la época emancipadora y primeros años de la república con destacada participación en la historia del Perú

Tiene la Casona de San Marcos, tres etapas bien definidas desde su creación, según Casalino C, (2017), quien señala a la historia de San Marcos como compleja señalando tres etapas, la primera como colonizadora junto con la labor evangelizadora; que abarca desde su creación en 1551 hasta 1850, la segunda como universidad nacional, caracterizada por la modernización y profesionalización, que data desde 1850 hasta 1919; y la tercera democratizadora que inicia en 1919 hasta nuestros días, siguiendo los dictámenes de la reforma universitaria hasta el 
2014 que se promulga la nueva ley actual que nos rige, la N. ${ }^{\circ} 30220$.

\section{MÉTODOS}

El método empleado fue aplicativo, transversal, no experimental. Se consideraron variables independiente y dependiente, siendo Identidad y Patrimonio, la independiente (X) y Turismo, respectivamente como dependiente, (Y). No se manipula ninguna de las variables y se observa el fenómeno tal cual. Como se puede apreciar en la Tabla 1, tanto la variable independiente como la variable dependiente tienen dimensiones e indicadores.

\section{RESULTADOS}

La observación en la investigación realizada en las visitas de campo, en ambos monumentos culturales fue realizada sin la participación del investigador, a fin de evitar el impacto a través de la conducta, características y desenvolvimiento de los visitantes. Esto se hizo para obtener una información más veraz a través de una actuación normal. Así mismo, se realizaron entrevistas a dos dominicos y un laico comprometido, para ser utilizada como una herramienta cuyo propósito es obtener, de primera fuente, elementos de análisis para concluir acertadamente la propuesta a realizar y fundamentar el estudio.

Para calcular la población se realizó un cálculo de promedio ponderado de días de visita, tomando en consideración que la fluctuación de visitas fue entre 200 y 300 personas diarias. Para el cálculo de dicha población se realizó la técnica de la observación de lunes a domingo por un mes, y se muestra la afluencia promedio por día/semana en la Tabla 2.

Los instrumentos son de orden cuantitativo y cualitativo, los cuales se aplicaron a los vi-

Tabla 1

Matriz de Operacionalización de las variables

\begin{tabular}{|c|c|c|}
\hline VARIABLE & DIMENSIONES & INDICADORES \\
\hline \multicolumn{3}{|l|}{ Independiente } \\
\hline $\begin{array}{l}\text { (X) Identidad y patrimonio } \\
\text { Conjunto de características y valores } \\
\text { propios de la sociedad peruana con un le- } \\
\text { gado patrimonial que distingue a la cultura } \\
\text { peruana por sus convicciones y significado } \\
\text { para la Historia del Perú. }\end{array}$ & $\begin{array}{l}\text { X1= Legado Cultural } \\
\text { X2 Hechos importantes que son reconoci- } \\
\text { dos Por su significado y trascendencia en la } \\
\text { historia. }\end{array}$ & $\begin{array}{l}\text { X1.= Nivel en que es reconocida en la histo- } \\
\text { ria el aporte de los dominicos y de la Casona } \\
\text { a la identidad peruana. } \\
\text { X2= nivel de importancia artística en Sto } \\
\text { Domingo y La Casona de San Marcos. }\end{array}$ \\
\hline \multicolumn{3}{|l|}{ Dependiente } \\
\hline $\begin{array}{l}\text { (Y) Turismo } \\
\text { Actividad que propicia el conocimiento y } \\
\text { difusión del patrimonio e identidad de la } \\
\text { sociedad peruana.. }\end{array}$ & $\begin{array}{l}\text { Y1= Nivel de Aceptación } \\
\text { de Santo Domingo y de La Casona en la } \\
\text { actividad turística } \\
\text { Y2= Valoración del conjunto } \\
\text { Arquitectónico y Artístico en } \\
\text { Turismo. }\end{array}$ & $\begin{array}{l}\text { Y1=. Determinar acciones que permitan } \\
\text { valorar el producto y lograr su gestión en } \\
\text { turismo. } \\
\text { Y2 = Destacar la importancia y valoración } \\
\text { de ambos monumentos como aporte cultur- } \\
\text { al al turismo. }\end{array}$ \\
\hline
\end{tabular}

Fuente: Elaboración propia

Tabla 2

Afluencia promedio de visitantes a Santo Domingo (de primera fuente)

\begin{tabular}{|c|c|c|c|c|c|c|c|c|}
\hline \multirow{8}{*}{$\begin{array}{l}\text { Días del mes } \\
\text { de agosto }\end{array}$} & Lu 08 & Ма 09 & Mié 10 & Jue 11 & Vie 12 & Sáb 13 & Dom 14 & Total \\
\hline & 150 & 180 & 200 & 256 & 280 & 200 & 270 & 219 \\
\hline & Lu 15 & Ma 16 & Mié 17 & Jue 18 & Vie 19 & Sáb 20 & Dom 21 & Total \\
\hline & 175 & 201 & 273 & 280 & 282 & 130 & 252 & 228 \\
\hline & Lu 22 & Ma 23 & Mié 24 & Jue 25 & Vie 26 & Sáb 27 & Dom 28 & Total \\
\hline & 185 & 212 & 214 & 281 & 133 & 200 & 277 & 215 \\
\hline & Lu 29 & Ma 30 & Mié 31 & & & & & Total \\
\hline & 300 & 500 & 170 & & & & & 323 \\
\hline
\end{tabular}

Fuente: Elaboración propia (agosto, 2018) 
sitantes a Santo Domingo, a través de un cuestionario de diecisiete ítems, tanto nacionales como extranjeros, en número promedio de 246 personas por mes, lo que resultó de la aplicación del programa On Line Net Quest, con una muestra de 150 participantes: siendo hombres y mujeres de igual proporción (50\%). cada uno. En cuanto a la edad 33,33\% estuvieron entre 34 y 41 años; 32,67\% entre 26 y 33 años; 19,33\% entre 18 y 25 y, 14,67\% de 42 años o más. Por otro lado, la mayoría de ellos fueron extranjeros, con un $54.67 \%$, y nacionales un $45,33 \%$. En cuanto al tema de identidad y patrimonio resultó de gran influencia histórica y religiosa para el tema turístico cultural en Lima.
Entre otras, las preguntas de la encuesta en Santo Domingo dieron los siguientes resultados:

Interpretación. Se puede observar en la tabla $\mathrm{N}^{\circ} 3$ que, del total de 150 encuestados, el $60 \%$ realiza la visita con un programa de agencias de viaje; un $20 \%$ lo realiza por su cuenta y un $20 \%$ restante lo realiza individualmente, pero con guías del convento (ver figura 1).

Interpretación. Se puede observar en la tabla $\mathrm{N}^{\circ} 4$ que, del total de 150 encuestados, el $54,67 \%$ son visitantes extranjeros, mientras que el $45,33 \%$ son visitantes nacionales (ver figura 2).

Tabla 3

Modo de visita. ¿La visita la realiza con un programa de agencias de viajes, por su cuenta con guías escritaso individualmente con guías del convento?

\begin{tabular}{lcccc}
\hline \multicolumn{1}{c}{ Válido } & Frecuencia & \% & Porcentaje Válido & Porcentaje Acumulado \\
\hline por su cuenta individualmente con guías & 30 & 20,0 & 20,0 & 80,0 \\
del convento & 30 & 20,0 & 20,0 & 100,0 \\
Total & 150 & 100,0 & 100,0 & \\
\hline
\end{tabular}

Fuente: Elaboración propia (2018)

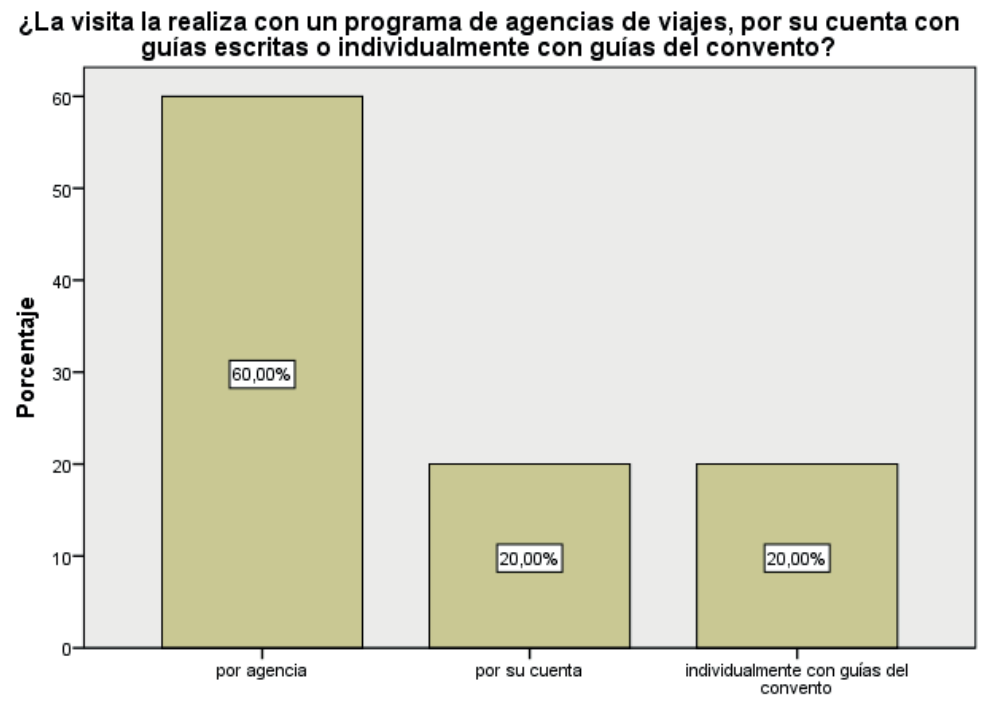

¿La visita la realiza con un programa de agencias de viajes, por su cuenta con guías escritas o individualmente con guías del convento?

Figura 1. Modo de visita.

Elaboración propia (2018)

Tabla 4

Nacionalidad de los visitantes

\begin{tabular}{llcccc} 
& & Frecuencia & Porcentaje & Porcentaje válido & Porcentaje acumulado \\
\hline \multirow{3}{*}{ Válido } & Peruanos & 68 & 45,3 & 45,3 & 45,3 \\
& Extranjeros & 82 & 54,7 & 54,7 & 100,0 \\
& Total & 150 & 100,0 & 100,0 & \\
\hline
\end{tabular}

Fuente: Elaboración propia (2018) 
Interpretación. Se puede observar en la tabla N. 5 que, del total de 150 encuestados, el $40 \%$ de visitantes nacionales tienen como principal motivación de visita una promesa o devoción a santos peruanos; mientras que el $60 \%$ lo hacen por la misma basílica y los santos peruanos (ver figura 3).
Interpretación. Se puede observar en la tabla $N^{\circ}{ }^{\circ} 6$ que, del total de 150 encuestados, el $60 \%$ de visitantes nacionales estudiantes proceden de colegios, el $20 \%$ proceden de universidades y estudios superiores y el $20 \%$ restante de otros centros educativos privados (ver figura 4).

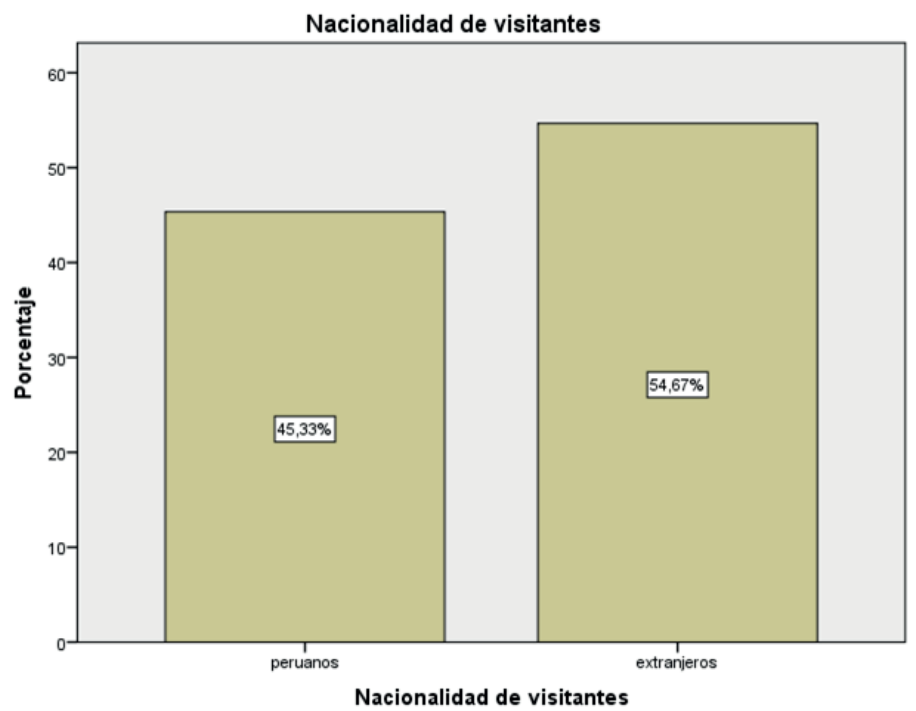

Figura 2. Nacionalidad de los visitantes (2018). Elaboración propia.

Tabla 5

Motivación de los visitantes nacionales

\begin{tabular}{llcccc} 
& & Frecuencia & Porcentaje & Porcentaje válido & Porcentaje acumulado \\
\hline \multirow{2}{*}{ Válido } & Basílica y santos peruanos & 90 & 60,0 & 60,0 & 60,0 \\
& promesa y devoción a santos peruanos & 60 & 40,0 & 40,0 & 100,0 \\
& Total & 150 & 100,0 & 100,0 \\
\hline
\end{tabular}

Fuente: Elaboración propia (2018)

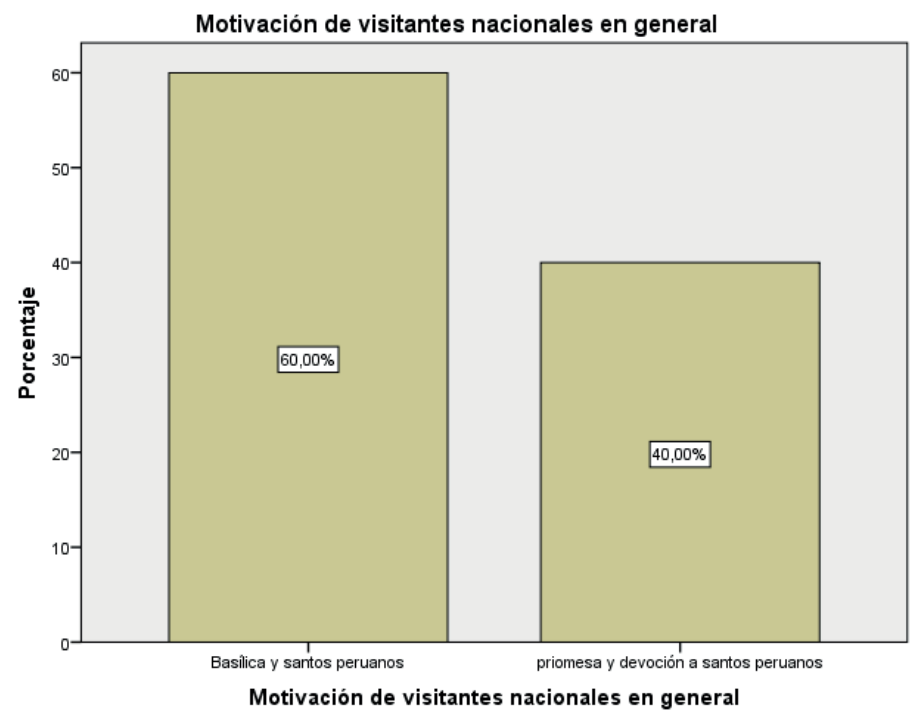

Figura 3. Motivación de los visitantes nacionales (2018). Elaboración propia. 
Interpretación. Se puede observar en la tabla $\mathrm{N}^{\circ} 7$ que, del total de 150 encuestados, el $70 \%$ de visitantes extranjeros visitan el convento por conocer la basílica y los santos peruanos; mientras que el 30\% lo hacen por una promesa y devoción a Santa Rosa y a San Martín (ver figura 5).

Interpretación. Se puede observar en la tabla N. ${ }^{\circ} 9$ que, del total de 150 encuestados, el $40 \%$ que visitan el convento de Santo Domingo son de nacionalidad mexicana; el $18 \%$ de nacionalidad, española; el 19,33\% son sudamericanos; el $15,3 \%$, colombianos; y el 7,33\%, de otras nacionalidades (ver figura 6).
Interpretación: Se puede observar en la tabla N. ${ }^{\circ} 12$ que, del total de 150 encuestados, el $40 \%$ conoce el conjunto monumental a través de internet, un $20 \%$ por medio de guía turísticas escritas y un $20 \%$ también afirma que conoce el conjunto monumental por amistades; finalmente se puede analizar que un 15,3\% lo hace a través de libros y un $4,7 \%$ por la oficina de la Municipalidad de Lima (ver figura 7).

Interpretación. Se puede observar en la tabla N. ${ }^{\circ} 14$ que, del total de 150 encuestados, el $75,3 \%$ no conoce que en este Convento se fundó nuestra universidad; mientras que un $24,67 \%$ sí tiene conocimiento sobre ello (ver figura 8).

Tabla 6

Visitantes nacionales (estudiantes)

\begin{tabular}{llcccc} 
& & Frecuencia & Porcentaje & Porcentaje válido & Porcentaje acumulado \\
\hline \multirow{2}{*}{ Válido } & Colegios & 90 & 60,0 & 60,0 & 60,0 \\
& universidad y estudios sups & 30 & 20,0 & 20,0 & 80,0 \\
& otros motivos & 30 & 20,0 & 20,0 & 100,0 \\
\hline
\end{tabular}

Fuente: Elaboración propia (2018)

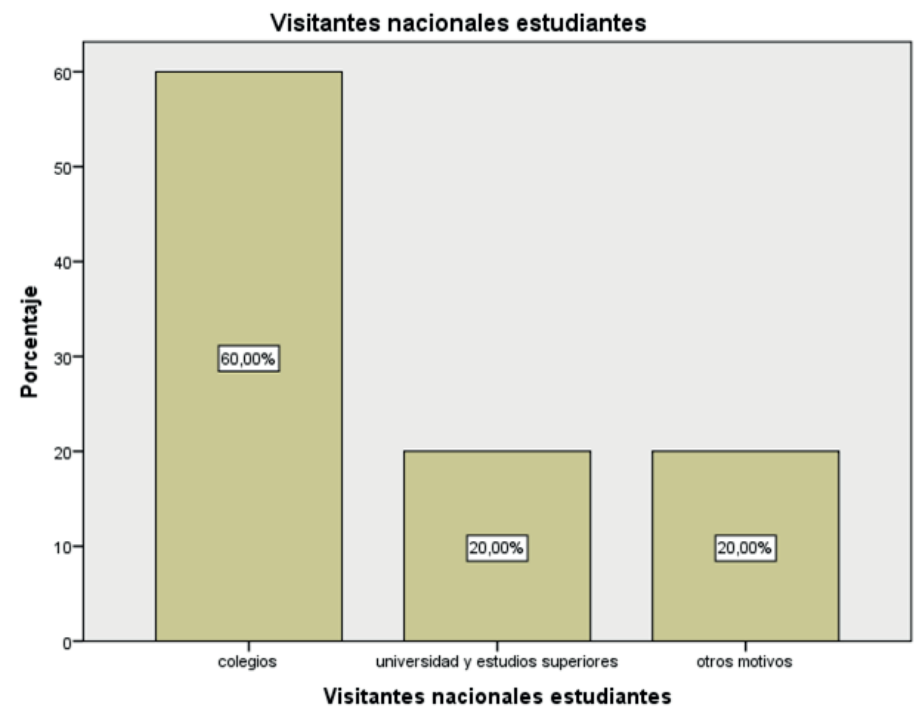

Figura 4. Visitantes nacionales estudiantes (2018).

Elaboración propia.

Tabla 7

Motivación de visitantes extranjeros

\begin{tabular}{|c|c|c|c|c|c|}
\hline & & & & & \\
\hline & & Frecuencia & Porcentaje & Porcentaje válido & Porcentaje acumulado \\
\hline \multirow{3}{*}{ Válido } & conocer la basílica y santos peruanos & 105 & 70,0 & 70,0 & 70,0 \\
\hline & promesas y devoción a Santa Rosa y San Martín & 45 & 30,0 & 30,0 & 100,0 \\
\hline & Total & 150 & 100,0 & 100,0 & \\
\hline
\end{tabular}

Fuente: Elaboración propia (2018) 


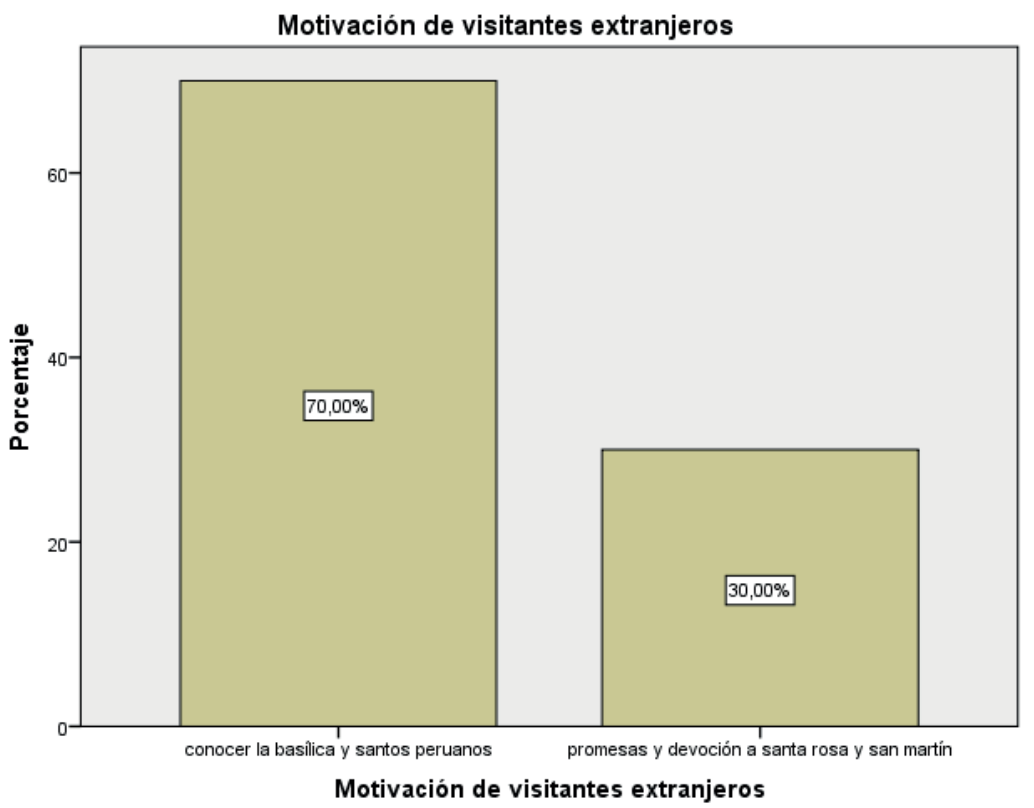

Figura 5. Motivación de visitantes extranjeros (2018).

Elaboración propia.

Tabla 8

Visitas por nacionalidades

\begin{tabular}{llcccc} 
& & Frecuencia & Porcentaje & Porcentaje válido & Porcentaje acumulado \\
\hline \multirow{2}{*}{ Válido } & Colombianos & 23 & 15,3 & 15,3 & 15,3 \\
& Mexicanos & 60 & 40,0 & 40,0 & 55,3 \\
& Españoles & 27 & 18,0 & 18,0 & 73,3 \\
& otros sudamericanos & 29 & 19,3 & 7,3 & 100,0 \\
\hline
\end{tabular}

Fuente: Elaboración propia (2018)

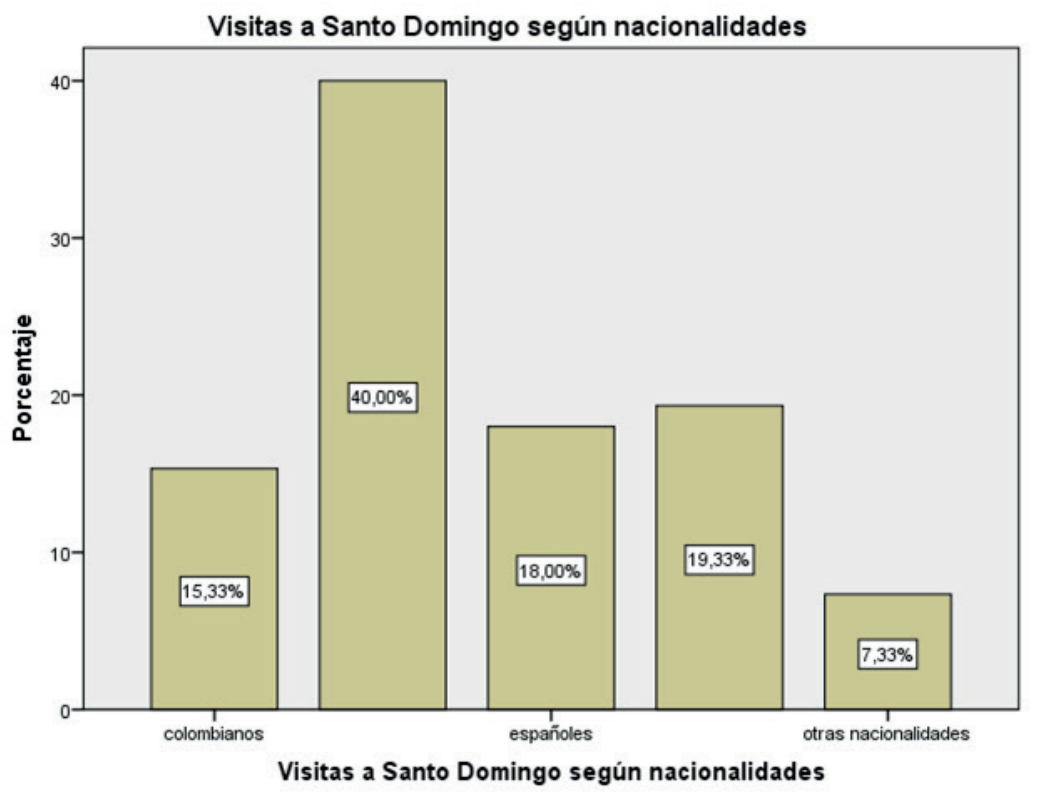

Figura 6. Visitas según nacionalidades (2018).

Elaboración propia. 
Interpretación: Se puede observar en la tabla N. ${ }^{\circ} 9$ que, del total de 150 encuestados, el $70 \%$ reconoce la importancia que trae consigo la formación educativa de los peruanos y el $30 \%$ no reconoce (ver figura 9).

Interpretación: Se puede observar en la tabla N. ${ }^{\circ} 20$ que, del total de 150 encuestados, el $66 \%$ cree que debe valorarse más a Santo Domingo en lo cultural y turístico, particularmente por sí solo; mientras que el $34 \%$ cree que debe incluirse otro conjunto monumental religioso similar (ver figura 10).

Respecto a La Casona, se pudo realizar un sondeo de la llegada de sus visitantes, siendo la Dirección de Turismo del Centro Cultural de San Marcos, (CCSM), quien promueve y organiza las visitas, siendo los escolares los que en mayor número la visitan, seguidos por naciona-

Tabla 9

Motivo de conocimiento del conjunto monumental de Santo Domingo

\begin{tabular}{|c|c|c|c|c|c|}
\hline & & \\
\hline & & Frecuencia & Porcentaje & Porcentaje válido & Porcentaje acumulado \\
\hline \multirow{6}{*}{ Válido } & por guías turísticas escritas & 30 & 20,0 & 20,0 & 20,0 \\
\hline & por internet & 60 & 40,0 & 40,0 & 60,0 \\
\hline & por libros & 23 & 15,3 & 15,3 & 75,3 \\
\hline & por amistades & 30 & 20,0 & 20,0 & 95,3 \\
\hline & Por Of. de Información MML & 7 & 4,7 & 4,7 & 100,0 \\
\hline & Total & 150 & 100,0 & 100,0 & \\
\hline
\end{tabular}

Fuente: Elaboración propia (2018)

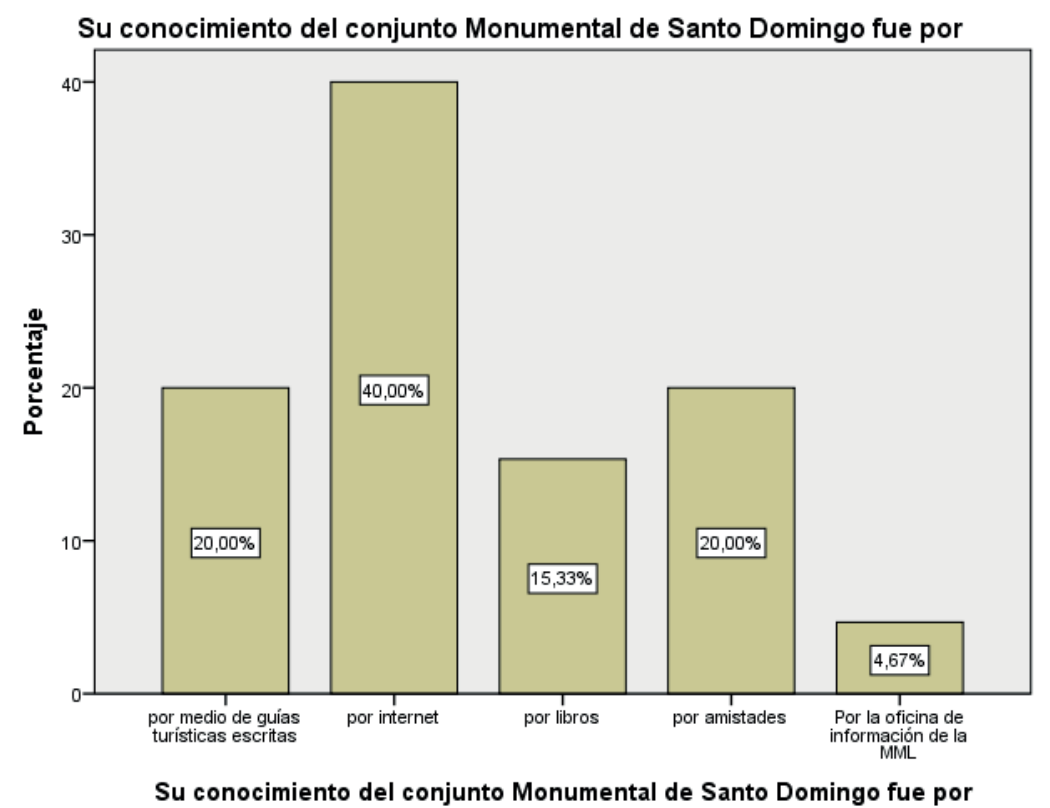

Figura 7. Motivo de conocimiento del Conjunto monumental (2018).

Elaboración propia.

Tabla 10

Conocimiento sobre la relación del convento con la UNMSM

\begin{tabular}{cccccc} 
& & Frecuencia & Porcentaje & Porcentaje válido & Porcentaje acumulado \\
\hline \multirow{3}{*}{ Válido } & Si & 37 & 24,7 & 24,7 & 24,7 \\
& No & 113 & 75,3 & 75,3 & 100,0 \\
& Total & 150 & 100,0 & 100,0 & \\
\hline
\end{tabular}

Fuente: Elaboración propia (2018) 


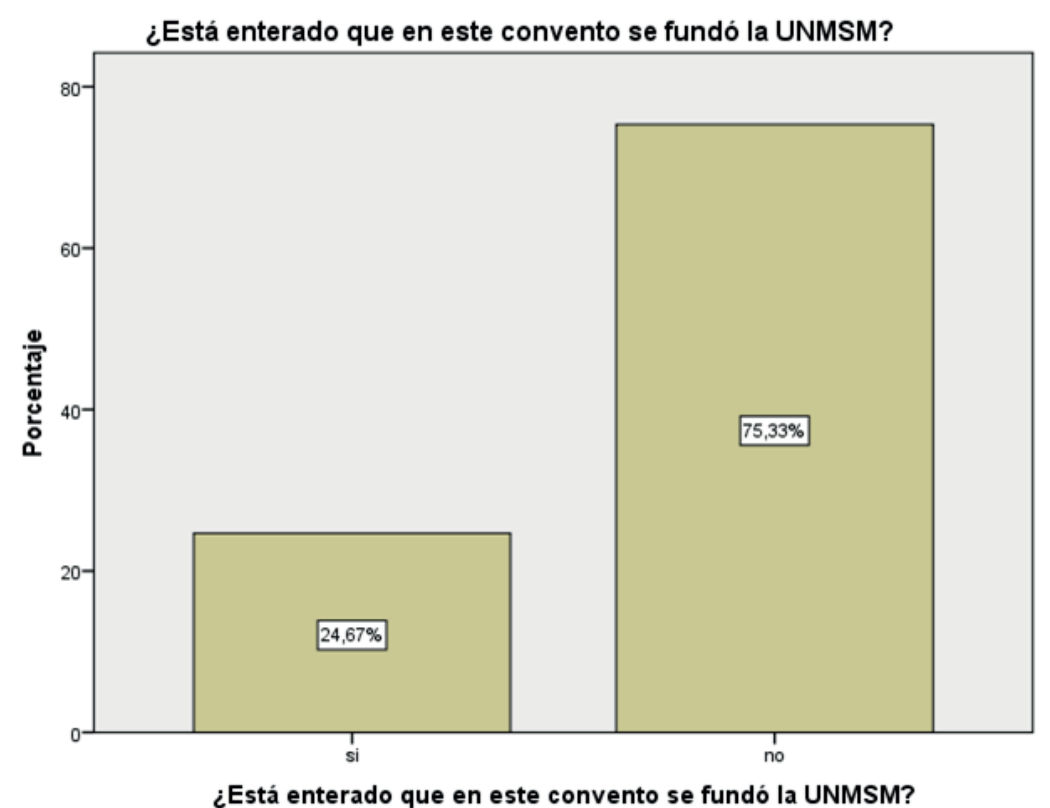

Figura 8. Conocimiento sobre la relación con la UNMSM 82018).

Elaboración propia.

\section{Tabla 11}

Conocimiento sobre la fundación de la universidad y reconocimiento de su importancia

\begin{tabular}{llcccc}
\cline { 3 - 6 } & & Frecuencia & Porcentaje & Porcentaje válido & Porcentaje acumulado \\
\hline \multirow{3}{*}{ Válido } & si & 105 & 70,0 & 70,0 & 70,0 \\
& no & 45 & 30,0 & 30,0 & 100,0 \\
& Total & & 100,0 & 100,0 & \\
\hline
\end{tabular}

Fuente: Elaboración propia (2018)

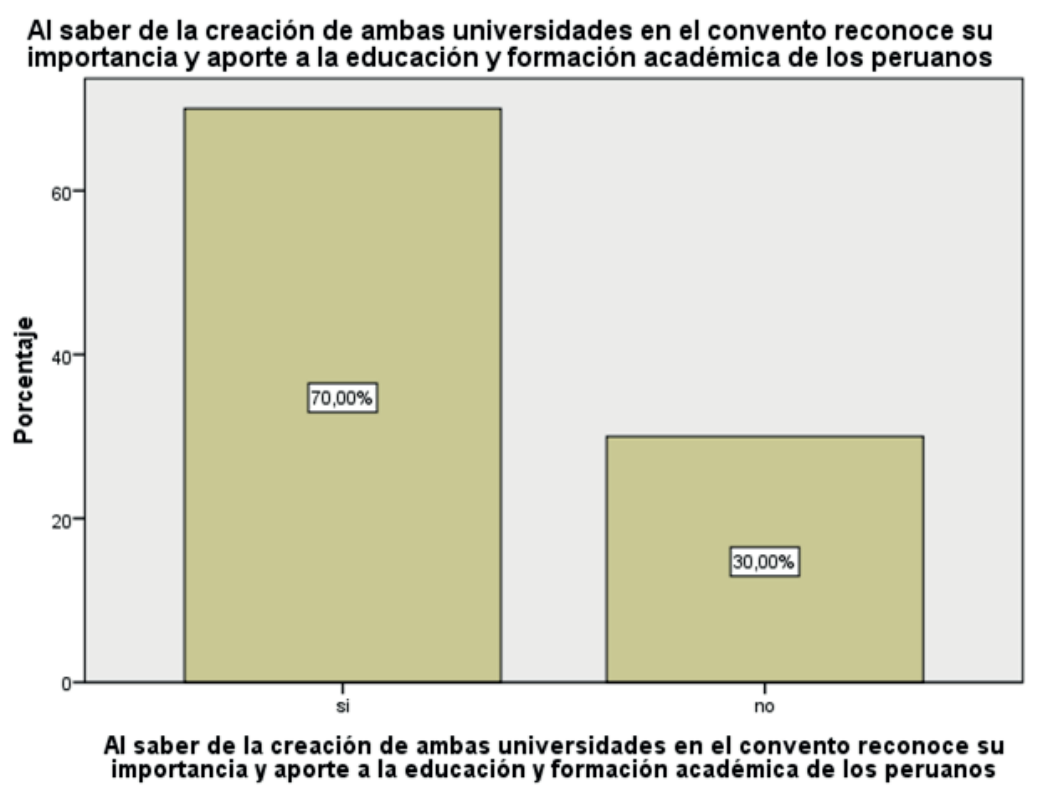

Figura 9. Reconocimiento sobre la importancia de la fundación de la Universidad (2018).

Elaboración propia. 
Tabla 12

Importancia de la valoración del atractivo

\begin{tabular}{llcccc} 
& & Frecuencia & Porcentaje & Porcentaje válido & Porcentaje acumulado \\
\hline \multirow{3}{*}{ Válido } & $\mathrm{Si}$ & 99 & 66,0 & 66,0 & 66,0 \\
& u otro conjunto monumental religioso similar & 51 & 34,0 & 34,0 & 100,0 \\
& Total & 150 & 100,0 & 100,0 & \\
\hline
\end{tabular}

Fuente: Elaboración propia (2018)

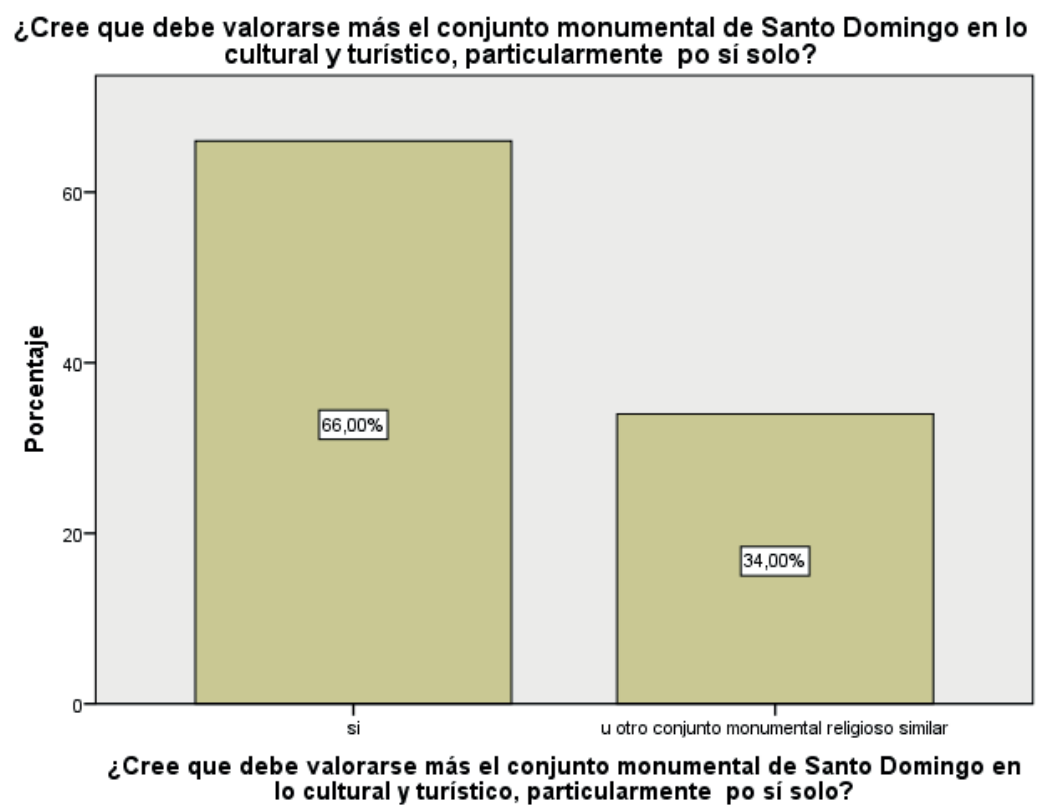

Figura 10. Importancia de la valoración del atractivo (2018).

Elaboración propia.

les y también extranjeros que por la poca cantidad de visitantes que recibe, no llega a situarse como un atractivo principal que merece un mayor reconocimiento y valor que verdaderamente le corresponde por las razones expuestas en el desarrollo de la presente investigación. Es por ello el interés de revalorar y gestionar acciones que la sitúen como museo en el sitial que le corresponde.

La Dirección de Turismo, propicia y difunde los atributos y valor cultural de La Casona, con eventos de tipo cultural y seminarios que contribuyen a destacar su promoción turística y aportes que benefician y actualizan información sobre la actividad turística. Así mismo se dan en La Casona visitas guiadas por los alumnos y estudiantes de turismo provenientes en su mayoría de la Escuela Profesional de Administración de Turismo de la UNMSM, quienes son preparados y capacitados para este fin, destacando su arquitectura, valor cultural e identidad para con la historia del Perú, recorriendo sus hermosos ambientes y patios dignos de ser admirados en su interior, bella muestra museística de tiempos virreinales y emancipadores.

\section{DISCUSIÓN}

El turismo beneficia la economía y por ello se convierte en una herramienta generadora de actividades directa e indirectamente relacionadas con otras actividades productivas conexas, ayuda a la sostenibilidad de la comunidad y garantiza la conservación y prestación de servicios teniendo como base al patrimonio inmueble como elemento fundamental para el fomento de la competitividad de un sector económicamente estratégico para el Perú, como es el turismo.

Si no se muestra interés en este relicto patrimonial es justamente por la falta de información y hasta de formación acerca de lo que 
representa tanto Santo Domingo como La Casona de San Marcos. Es importante y necesario revalorar el patrimonio que poseen, que permita destacar sus atributos físicos, artísticos y patrimoniales.

En el plano de la identidad, se ha analizado el tema desde el punto de vista antropológico, sociológico, psicológico, religioso e histórico. En tal sentido, autores como Matos Mar, Victor Andrés Belaunde, Max Hernández, Salgado Lévano, Santo Toribio de Mogrovejo y Porras Barrenechea se refieren al tema de identidad desde su perspectiva ocupacional y profesional, pero lo importante es que todos coinciden en que el peruano aún no refleja ni tiene un sentimiento unitario al respecto; se preguntan quiénes somos los peruanos, los de arriba, los de abajo, la falta de equidad, la regionalización y ahora más contemporánea, el tema de la globalización, son problemas que se afrontan y se suman a una población que tiene muchos elementos comunes y a su vez, desiguales en género, etnias, posición social, económica y cultural, de manera que estos elementos, en lugar de unirnos, nos separan aún más.

Esa falta de sensibilidad y la voluntad de actuar igualitariamente ante la justicia y orientados a intereses comunes (no de conveniencia e intereses creados), ahondan el problema de tener una sola identidad peruana a pesar de tantas diferencias y reconocernos como mestizos.

La importancia que tienen, así como la relación entre ambos monumentos arquitectónicos están directamente relacionadas en su historia e identidad, siendo el turismo la herramienta que permite la valoración que les corresponde como atractivos culturales en los aspectos religioso, artístico y académico influyendo y aportando con sus acciones del pasado en la creación de la identidad peruana. La actividad turística permite en sí misma la multiplicidad de opciones, lo cual potencia el interés de diferentes ángulos en el ámbito turístico, actividades como eventos, estudios, investigación, entre otros, complementando lo que puede motivar la visita a ambas entidades patrimoniales peruanos.

Los resultados más relevantes son los siguientes:
1. Se requiere una mayor concientización y salvaguarda del patrimonio, lo cual supone una mayor valoración de ambos monumentos históricos. Por ello se deben implementar acciones con los actores involucrados como la comunidad limeña, municipio, entidades y organismos relacionados directa e indirectamente con el turismo.

2. A través del turismo, se propicie a ambos monumentos histórico religioso culturales, visitas y actividades que generen conocimiento, promoción y valores del patrimonio en mención a un público objetivo y beneficios redituables y de posicionamiento siendo la actividad turística la mejor vía para lograr estos objetivos propuestos.

\section{CONCLUSIONES}

La Identidad del peruano y valor del Patrimonio inmueble de Santo Domingo y La Casona son monumentos arquitectónicos que tienen mucha importancia dentro de la historia y significan etapas importantes en la vida cultural del Perú.

Su bagaje histórico religioso de Santo Domingo y cultural, de la Casona, permite a la actividad turística destacar al Perú como un destino netamente cultural por ser Lima, denominado por UNESCO Patrimonio Cultural de la Humanidad, que evidencian la existencia de tiempos coloniales con su arquitectura que destaca en la ciudad de Lima.

Identidad y Patrimonio, se relacionan directamente a fin de consolidar una nacionalidad peruana sobre un territorio con autenticidad, pasado común, un presente y futuro prometedor que es original y diferenciado por una idiosincrasia particular que se refleja en los sentimientos, hospitalidad y humildad del peruano de bien, con usos y costumbres forjados a través del tiempo y dio por resultados una identidad que surge en un momento crucial de lo virreinal a movimiento independentista y posterior etapa republicana en el Perú.

\section{RECOMENDACIONES}

Difundir y promocionar las acciones turísticas y culturales que actualmente se ofrece en ambos monumentos, a través de: 
- Coordinaciones necesarias con las autoridades competentes vinculadas para motivar investigaciones y especialización respecto a estudios a fin de revalorarlas.

- Promover, en ambos monumentos, actividades que logren mayor difusión para su conocimiento a nivel nacional e internacional, dándole el verdadero valor que posee y significa.

- En La Casona, desarrollar eventos que le permitan potenciar sus oportunidades de fomento y desarrollo cultural, por la riqueza tangible e intangible que posee como parte del Centro Histórico de Lima.

- Proponer circuitos turísticos que incluyan otros atractivos de la periferia del Centro Histórico de Lima.

\section{REFERENCIAS BIBLIOGRÁFICAS}

Álvarez, G. O. P. (1996). La Orden dominica en el Perú en el siglo XIX. Revista Peruana de Historia Eclesiástica.5, 33-72.

Bákula, C. (2000). Reflexiones en torno al patrimonio cultural. Revista Turismo y Patrimonio, 1
Belaúnde, V. A. (1957). Peruanidad. Publicaciones del Instituto Riva Agüero. Lima: Librería Studium.

Casalino, C (2017). Tres etapas y dos personales ilustres en la historia de la Universidad Nacional Mayor de San Marcos. Investigaciones Sociales 38

Castillo Yui, N. C. (2007). Teoría y Técnicas del Turismo y la Hotelería II. Lima: UIGV.

Giddens, A. (1997). Modernidad e identidad del yo: el yo y la sociedad en la época contemporánea. Barcelona: Península.

Hernández, M. (2000). ¿Es otro el rostro del Perú? Identidad, diversidad y cambio. Lima: Agencia.

Hernández, R., Fernández, R., \& Baptista, P. (2014). Metodología de la Investigación (6ta ed.). México: McGraw-Hill.

Leuridan-Huys, J. (2014). La Familia, la escuela y los líderes de la sociedad. Cultura 28.

Matos-Mar, J. (1984). Desborde popular y crisis del Estado. El nuevo rostro del Perú en la década de 1980. Lima: IEP - Instituto de Estudios Peruanos.

San Cristóbal, A. (2012). Arte Virreinal de la Iglesia y Convento de Santo Domingo. Lima: USMP.

Santana, A. (1997). Antropología y turismo, ¿Nuevas hordas, viejas culturas? Barcelona: Ariel. 
